The Geographical Journal of Nepal

Vol. 11: 127-136, 2018

Central Department of Geography,

Tribhuvan University, Kathmandu, Nepal

\title{
An assessment of earthquake risk in Thecho of Kathmandu valley Nepal: Scenario and reality
}

\author{
Sony Maharjan; and Shobha Shrestha* \\ Central Department of Geography, Tribhuvan University, Kathmandu, Nepal \\ (*Corresponding Author: shova216@gmail.com)
}

Natural disaster cannot be stopped but its effect can be minimized or avoided by adopting technology and necessary human adjustment. Earthquake is a natural event which occurs without early warning signs. Computer based earthquake scenarios are used worldwide to describe and estimate the damage from potential earthquakes. The current study is an attempt to explore potential risk with respect to physical infrastructure and assess modeled and actual physical damage and human loss caused by different earthquake scenario and actual 2015 earthquake event in Thecho of Kathmandu valley. The earthquake scenario is based on two nearest fault lines. Risk Assessment Tools for the Diagnosis of Urban Seismic Risk (RADIUS) method has been applied for estimation of potential building damage and casualties.. The research has adopted integrated approach using secondary and primary data sources such as field observation, key informant survey and building survey through purposive random sampling. The study found that potential building damage estimated by RADIUS for Gorkha 2015 earthquake scenario and North-west (Khokana) are lower than the actual postearthquake assessment whereas North earthquake scenario resulted higher loss. Actual damage caused by 2015 earthquake compared to modeled damage from RADIUS is found higher because additional damaged were made by successive aftershocks. Spatial distribution of potential building damage for earthquake scenarios and actual 2015 earthquake event is also variable. North-Nuwakot Earthquake Scenario resulted more hazardous than the North-Khokana scenario though the location of epicenter is relatively farther with high intensity. The study concluded that though earthquake occurrence and disaster is still less predictable risk assessment tools like RADIUS and mitigation measures based on such is important for reducing risk of earthquake disaster.

Keywords:Earthquake; disaster; scenario analysis; building vulnerability; RADIUS; risk assessment; awareness and preparedness 


\section{Introduction}

Earthquake is one natural event which gives severe threat due to the irregular time intervals between events and lack of adequate forecasting. Nepal was ranked twentythird in the world in terms of total natural hazard related to death and eleventh in the world in terms of vulnerability to earthquakes (UNDP/ERRRP, 2009).National Seismological Center of Nepal has recorded large earthquakes in the Himalayas like The Kangra- India earthquake of 1905, the Bihar-Nepal earthquake of 1934, and the Assam-India earthquake of 1950; those were all about 8.5 magnitude earthquakes. The 1980 earthquake with epicenter in Bajhang district and 1988 earthquake with its epicenter in Udayapur both measured 6.6 Richter scale and the recent one was April, 2015 earthquake which had its epicenter in Gorkha and measured 7.6 Richter scale which in total damaged 356000 building and more than 25000 human death (NSET, 2004; USGS, 2015). Nepal has a complex geological structure with active tectonic process and continued seismic activities. It is located along the active faults between tectonic plates which is one of the seismic prone area (Karanth, 2002; NSET-Nepal, 2012). It is observed that when tectonic plates push against each other earthquake occurs and it has relationship with the fault boundaries. There are ninety-two active faults in Nepal and the immediate cause of most earthquakes in the country is faulting; the process of breaking and movement of rocks (Karanth, 2002).

The most of the deaths from earthquakes are caused by buildings or other construction falling down during an earthquake which always could not be possible to avoid and earthquake itself does not kill people but human made structures do (Shah, 2003). Earthquake disaster and damage and loss depends on three major factors namely, population density, construction standards, and emergency preparedness (Nelson, 2002).

Risk Identification is the first step to disaster risk management for identifying and understanding the scale of problem. Vulnerability analysis is one of the component of risk identification. Earthquake scenarios analysis are common approach used to estimate potential damage from earthquakes. Such analysis help communities identify necessary earthquake risk management programs and minimize the loss. In this context, this current study is an attempt to explore vulnerability to earthquake in Thecho based on potential earthquake scenario using RADIUS approach and to assess 2015 post earthquake physical and human damage.

\section{Methods and materials}

The study area Thecho, ward number 12 of Godawari Municipality is located in Lalitpur district of Kathmandu valley, Nepal (Figure 1). It is about 1371 meter high from sea level and covered area of $3.32 \mathrm{sq}$. km. The total population is 10086 (CBS, 2011) among || $128 \|$ 
which 4942 are male and 5144 are female. It is multicultural but majority of the people belongs to Newar ethnic community followed by, Brahamin-Chhettri, Tamang, Rai and Magar. Agriculture is the major occupation of the most of the people and seventy nine percent of the total area is covered by cultivation.
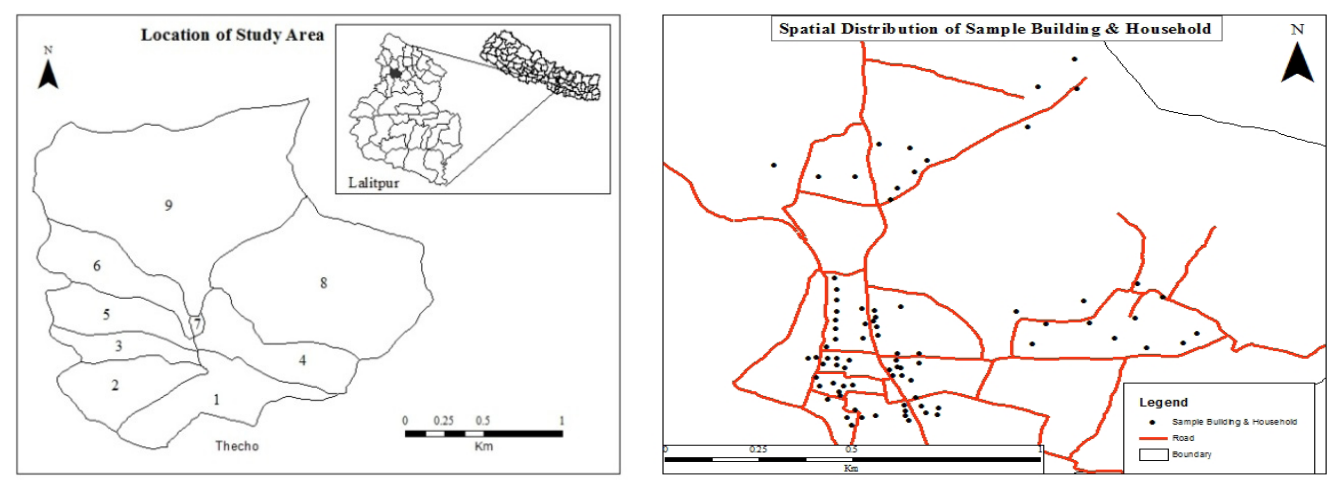

Figure 1: Location of study area and sample building distribution

Major lifeline in the study area includes drinking water supply, electricity, road and telecommunication. Drinking water has been supplied by Nepal Drinking Water Corporation. It encompasses 85.48 meter of black topped road, 22 meter of stone paved road and more than 70 meter of gravel and other roads. Electricity is supplied in two different capacities: high voltage of 11000 volt and low voltage of 220 volt (VDC office Thecho, 2008; NRCS, 2015).

The current paper is based on primary data collected from detailed fieldwork and secondary information. Buildings are taken as sampling unit and stratified random sampling method was applied for selecting sample buildings. Major criteria for selecting sample settlement and buildings was relative building density categorized as: old settlement (nucleated with old buildings), new settlement (dispersed with relatively new buildings) and open space (open space with few isolated buildings). In total 12 percent (687 buildings- 83 sampled) buildings were surveyed using building inventory sheet (Figure 1) assuming the distribution of the sample means is normally distributed (Thode. 2002). Representative sample of buildings covering 4 percent from each category were collected using building density criteria through stratified random sampling. The 2015 earthquake happened during the data compilation of building survey. So in order to verify modeled and actual earthquake damage, second stage building survey was carried out after 2015 earthquake. The same buildings were visited for repetitive survey after the earthquake. Field observation was also carried out using checklist for physical infrastructure like road, electricity and telecommunication for scenario analysis. Another 
method used was key informant interview to analyze historical record of earthquake occurrence and damages caused. Fifteen elderly people of age seventy and above from categorized settlements were interviewed as key informants. Besides, secondary data and information was collected from the VDC office (then), Central Bureau of Statistics (CBS), National Society for Earthquake Technology (NSET) and Department of Mines and Geology (DoMG).

Risk Assessment Tools for diagnosis of Urban Area against Seismic Disaster (RADIUS) is a computer based tool which has been used for scenario analysis to estimate the earthquake damage. RADIUS tool is developed by the Secretariat of the International Decade for Natural Disaster Reduction (1999-2000) of United Nations. The RADIUS initiative aimed to reduce seismic disasters in urban areas of developing countries taking nine selected cities as case studies to develop seismic damage scenario and risk assessment plan. The method includes the estimation of damage due to ground shaking. The tool allows vulnerability analysis of buildings based on parameters like construction material type, construction type, age of building, shape of building, roofing type, wall size, joint/disjoint neighbor and number of stories (Villaciset. al., 2000). Scale of vulnerability of building is based on parameter values and buildings are categorized into three class i.e. high, medium and low vulnerability. Two fault lines namely, Main Central Thrust (MCT) and Lesser Himalaya Thrust (LHT) as nearest reference to study area beside MCT for Gorkha earthquake were taken for analysis to measure the vulnerability on buildings and lifelines. Earthquake occurrence at two different time; Day time and night time were modeled. Beside actual earthquake damage caused by 2015 Gorkha earthquake was cross-referenced. The earthquake scenario analysis is carried out by defining location of epicenter, magnitude and depth. Two nearest reference is taken for scenario are North-Nuwakot (MCT: magnitude 7.6, distance $37 \mathrm{Km}$, depth $20 \mathrm{Km}$ ) and North-Khokana (LHT: magnitude 6.5 , distance $2.55 \mathrm{Km}$ and depth $20 \mathrm{Km}$ ) whereas Gorkha scenario is modeled with the same parameters as the event occurrence (MCT: magnitude 7.8, distance 80Km and depth 15Km) (DoMG, 2006, Howard, 2015). Vulnerability functions, which indicate the relation between seismic intensity rate for structural types, are determined as the function of acceleration/MMI based on damage observed during past earthquake events. The damage levels considered in this method is collapses and heavy building damage. A uniform mesh spacing of $200 \mathrm{~m}$ to $5 \mathrm{~km}$ is usually recommended by considering the size area (Villacis et. al., 2000). The mesh spacing of $200 \mathrm{~m}$ is considered for estimation of the earthquake scenario in this study.

\section{Results and discussion}

Building vulnerability is attributed to various factors such as physical factors of building location like soil types, slope and fault line, construction factors like construction materials, height, age, roofing system, shape (geometry) etc. Socio-economic and 
cultural aspects such as level of people's awareness, knowledge and application also play the vital role to building vulnerability (Guragain, 2004). The presence of three main fault lines: the Main Central Thrust (MCT) at the foot of the Greater Himalaya joining the midland mountains, the Main Boundary Fault (MBF) at the junction of the Lesser Himalaya and the Siwaliks and the Himalayan Frontal Fault (HFF) south of the Siwaliks, each running east to west, are the main causes of earthquakes in Nepal (NSET, 2012). The nearest fault lines from the study area are Lesser Himalayan Fault (LHF) which is located at $2.55 \mathrm{~km}$ north-west and Main Central Thrust (MCT) located at $37 \mathrm{Km}$ north. The theoretical estimation is performed by combining the seismic intensity distribution that is estimated for the adopted earthquake with the inventory of the structures and infrastructure of the city. This combination is performed using vulnerability functions that are developed to reflect the seismic behavior of the structures and infrastructure found in the city (Chaudhari, 2008). Earthquake hazard is estimated from the parameters of the scenario earthquake and ground conditions. Ground shaking intensity of earthquake, PGA (peak ground acceleration) at the site generally becomes greater as the magnitude becomes larger or the distance from the site to the epicenter becomes smaller (Spence et al., 1989). Earthquake scenario hence is modeled to assess the physical distance of epicenter and potential damage with the nearest (North-Khokana), medium (NorthNuwakot) and far (Gorkha) distance epicenter location.

\section{North-Khokana Earthquake scenario}

The North-west earthquake scenario was applied to LHF fault line with seismic intensity of 6.5 magnitude at $2.55 \mathrm{Km}$ distance for the estimation of the potential building, lifeline and human loss vulnerability. The result showed that estimated potential damage would be 58.4 percent i.e. 955 buildings were found likely to be damaged, if the North-west Earthquake hits the study area. Regarding lifelines, the estimated damage is relatively low with less that 1 percent damage to all lifelines. When serious human injury and loss is concerned, the estimated injury and loss during night time disaster is higher in comparison to day time (Maharjan, 2016). However, human loss would be less than 1 percent while more than 8 percent of the total population would be seriously injured. Similar to North-Nuwakot earthquake scenario, spatial effect is highest in ward number 9 i.e. is the most vulnerable so far as location is concerned whereas ward number 6 is relatively less vulnerable.

\section{North-Nuwakot Earthquake scenario}

The North earthquake scenario was applied to MCT fault line with seismic intensity of 7.6 magnitude at $37 \mathrm{Km}$ distance for the estimation of the potential building, lifeline and human loss vulnerability. The result showed that estimated potential damage would be 78.3 percent i.e. 1280 buildings out of total 1635 were found likely to be damaged, 
if the North-Nuwakot Earthquake hits the study area. Regarding lifelines, the estimated damage is relatively low with lowest potential damage to telecommunication substations (1\%) and highest potential damage to telecommunication transmission lines $(15.2 \%)$. When serious human injury and loss is concerned, the estimated injury and loss during night time disaster is higher as compared to day time because during night time most of the people are assumed to be inside their houses. It is found that if earthquake resembling North-Khokana earthquake scenario characteristics hits the study area, more than 20 percent people would be seriously injured whereas 1.6 percent people would be dead. Ward number 9 of the study area is the most vulnerable so far as location is concerned whereas ward number 6 is relatively less vulnerable.

\section{Gorkha 2015 Earthquake scenario}

Devastating earthquake of magnitude of 7.6 hit Nepal on 2015 with epicenter located at $85 \mathrm{~km}$ northeast from the study area with the depth of $11 \mathrm{~km}$ in main central thrust, MCT fault line (USGS, 2015).Using same parameters as in North-Khokana and NorthNuwakot earthquake scenario, Gorkha earthquake scenario was also run using RADIUS for cross-referencing.It has resulted that 560 buildings would be fully damaged. Post-earthquake assessment revealed that there were 2 human deaths and 56 injuries while 628 buildings were fully damaged and 233 buildings were partially damaged. The heaviest building damage was caused in ward number $3(82 \%)$ followed by ward number $7(72 \%)$. The overall potential damage scenario and post-earthquake assessment of buildings by wards is summarized in Table 1 .

Table 1. Ward-wise potential and actual building damage

\begin{tabular}{|c|r|r|r|r|r|r|r|}
\hline Ward & $\begin{array}{c}\text { Total } \\
\text { Buildings }\end{array}$ & \multicolumn{5}{|c|}{ Potential damage } & \multicolumn{2}{c|}{ Actual damage } \\
\hline & & $\begin{array}{c}\text { North- } \\
\text { Khokana }\end{array}$ & $\begin{array}{c}\text { \% North- } \\
\text { Khokana }\end{array}$ & $\begin{array}{c}\text { North- } \\
\text { Nuwakot }\end{array}$ & $\begin{array}{c}\text { \% } \\
\text { North- } \\
\text { Nuwakot }\end{array}$ & Gorkha & $\begin{array}{c}\% \\
\text { Gorkha }\end{array}$ \\
\hline 1 & 266 & 103 & 39 & 133 & 50 & 139 & 52 \\
\hline 2 & 113 & 30 & 27 & 44 & 39 & 71 & 63 \\
\hline 3 & 126 & 37 & 29 & 48 & 38 & 103 & $\mathbf{8 2}$ \\
\hline 4 & 171 & 96 & $\mathbf{5 6}$ & 121 & $\mathbf{7 1}$ & 76 & 44 \\
\hline 5 & 122 & 34 & 28 & 47 & 39 & 72 & 59 \\
\hline 6 & 203 & 19 & 9 & 22 & 11 & 110 & 54 \\
\hline 7 & 76 & 35 & 46 & 44 & 58 & 55 & $\mathbf{7 2}$ \\
\hline 8 & 265 & 213 & $\mathbf{8 0}$ & 106 & 40 & 131 & 49 \\
\hline 9 & 452 & 213 & 47 & 320 & $\mathbf{7 1}$ & 104 & 23 \\
\hline Total & $\mathbf{1 6 3 5}$ & $\mathbf{7 7 9}$ & $\mathbf{4 8}$ & $\mathbf{1 0 4 4}$ & $\mathbf{6 4}$ & $\mathbf{8 6 1}$ & $\mathbf{5 3}$ \\
\hline
\end{tabular}




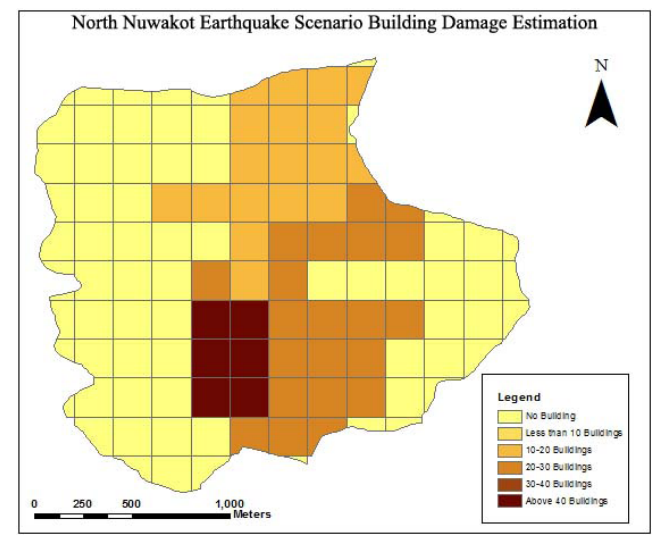

Figure 2a: potential building damage north Nuwakot earthquake

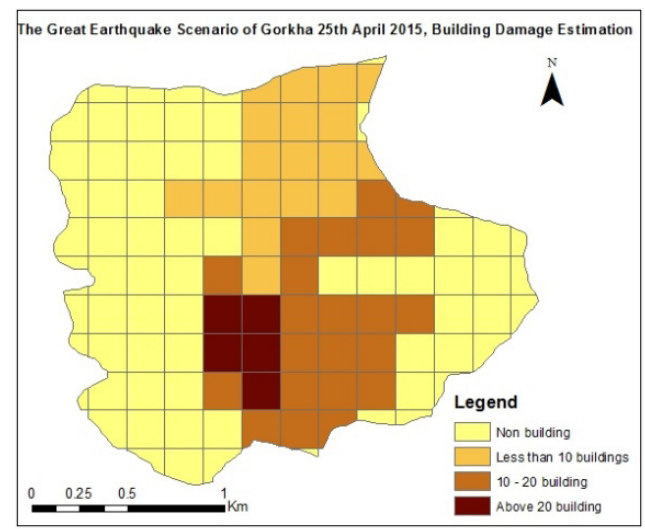

Figure 2c: potential building damage Gorkha 2015 earthquake

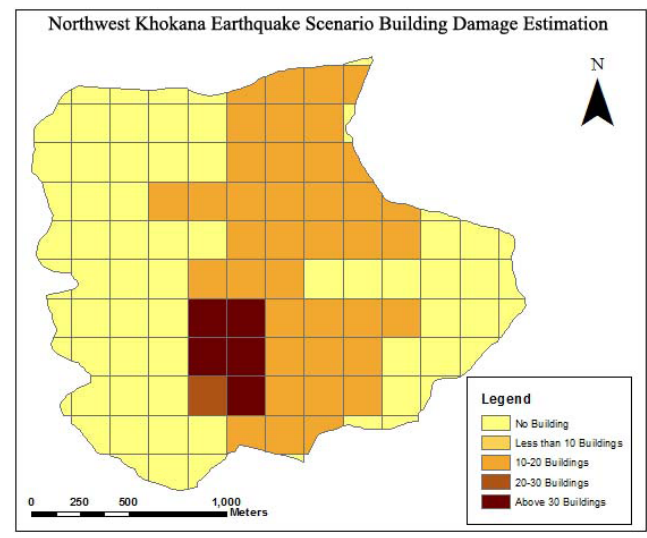

Figure 2b: potential building damage north -west Khokana earthquake

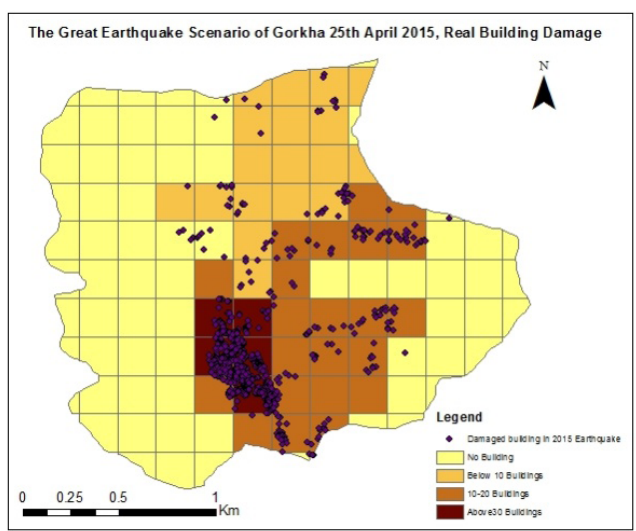

Figure 2d: actual building damage Gorkha 2015 earthquake

The intensity of an earthquake is a measure of the shaking created by the earthquake, and this value does vary with location. In the current case, North Nuwakot Earthquake Scenario resulted more hazardous than the North-West Earthquake scenario though the location of epicenter is relatively farther with high intensity. The estimated human causalities, building and lifelines damage is larger as compared to North-West Earthquake Scenario which has moderate impact. Studies show that though the intensity may be higher, level of vulnerability and actual damage varies based on the mitigation measures and adaptation to reduce its vulnerability (Walton, 2014). Two events of earthquake that occurred in the same year (2010) in Haiti with 7.0 magnitude, epicenter located at $25 \mathrm{Km}$ and depth of $13 \mathrm{Km}$ and Chile with 8.8 magnitude, epicenter located at $95 \mathrm{Km}$ and depth of $35 \mathrm{Km}$ has quite different impact. Haiti suffered substantial damage as compared to 
Chile because of the mitigation measures and adaptive strategies developed to tackle earthquake disaster. In case of Thecho, all three modeled scenario and actual earthquake case, heavier damage is towards south-central and eastern part because location of old settlement and clustering of new buildings is confined to these two directions. The result of study show that, age of building and construction material was dominant factor followed by cultural aspect of preparedness. It is found that 95 percent local people are aware of the earthquake risk and have experienced the degree of damage that could be caused. The role of individual household and community for mitigation measures such as personal safety, following building codes enforced by the authority, identifying open spaces etc are also realized by 85 percent people. But implementation of preparedness is relatively low with only 66 percent. The finding show that though the number and degree of building damage is variable in each of three modeled scenario as well as in actual earthquake event, location and direction of potential and actual damage area matches. The RADIUS method applied and tool used hence, is applicable and useful for identifying vulnerable areas.

Earthquake scenarios provide estimations which can be used to develop risk mitigation measures and reduce risk. However, degree of estimation may vary with available resources, organizations and experience. Nevertheless, Earthquake scenarios can help communities identify necessary earthquake risk management programs. Fast earthquake scenarios has been proposed to identify major earthquake risk and vulnerability in developing countries and one of them among many method is Risk Assessment Tools for the Diagnosis of Urban Seismic Risk, RADIUS (Villacis, et al., 2000). It is suggested that scenario analysis should be used to raise awareness and understanding among stakeholders and community to identify activities those could be implemented under limited resources to produce optimum benefits and to help create the social and political context for meaningful analyses (UNDP, 2013). Awareness of people and capacity building up of existing human resource and generation of human resource for emergency response in possible earthquake for rescue and medical care seem inevitable and Earthquake mitigation can be affordable and easy to do when taken in small steps (Arya \& Srivastava, 1998).

Intensity of earthquake is based on local acceleration and how long it persists. It also depends on variables like rock breaking process, energy travels from an earthquake to a receiver. However, it is still unknown how degree of intensity increases and how it impacts in a particular location (Spence et al, 1989). Hence scenario analysis together with review of the past disasters would allow the local authorities to identify the vulnerable locations and communities. The analysis of the impact of past disasters on various communities and social groups will help understand the relationship between the nature of hazard and the kind of impact they can have upon various at-risk-elements (Kafle \& Murshed, 2006). 


\section{Conclusion}

Scenario analysis of Thecho showed that it is highly vulnerable to earthquake risk because of settlement pattern, building age and construction materials beside preparedness culture. The vulnerability of building is not only dependent on the earthquake magnitude, distance from fault line, depth and direction, equally important is awareness and preparedness plan of local people. Preparedness over awareness should be hence emphasized to minimize the risk. Similarly, risk assessment tools and mitigation measures is important for reducing risk of earthquake disaster though it is not possible to exactly predict the earthquake occurrence.

\section{References}

Arya, A. B., \& Srivastava, A. B. (1998). Regional Development Dialogue. In A. A. Srivastava eds., Application of Research Findings in earthquake Disaster Preparedness Planning and Management (pp. P. 13-23). Nagoya Japan: United Nations Center for Regional Development.

CBS (2011). Nepal Census 2011. Kathmandu: Central Bureau of Statistic.

Chaudhari, S. (2008). Lifeline Seismic Damage Evaluation in A GIS Environment: A Case Study of Ilam Municipality, Eastern Nepal. M.A thesis, Central Department of Geography, T.U.

DoMG (2006). Seismic Hazard Map of Nepal. Kathmandu: Department of Mines and Geology (DoMG).

DPNet (2005). Disaster Preparedness Network. Activities Completion Report Series. Kathmandu: DPNet.

Guragain, J. (2004). GIS for seismic building loss estimation: A case study of Lalitpur sub metropolitan city. M. Sc thesis, international institute for Geo-information and Earth observation(ITC). Enschede, Netherlands.

Howard, B. C. (2015). Nepal Earthquake Strikes One of Earth's Most Quake-Prone Areas. National Geographic. Retrieved 27 April 2015

IIT. (2007). Handbook on Seismic Retrofit of Building. Central Public Works Department. Nirman Bhavan, New Delhi: Indian Institute of Techonology (IIT).

ISDR. (2003). International Strategy for Disaster Reduction.Latin America, Caribbean.

Jimee, G. K. (2006). Seisimic Vulnerability and Capacity Assessment at ward level; A case study of ward No 20, Lalitpur Sub -Metropolitan city. Enschede, Netherlands: M.Sc thesis, International Institute for Geo-Information Science and Earth Obserbation.

Kafle, S. K., \& Murshed, Z (2006) Community-based disaster risk management for local authorities.Bangkok, Thailand: Asian Disaster Preparedness Center (ADPC). 
Karanth, A. (2002). Seismic Risk Management of Katmandu Valley. Unpublished Dissertation Subbmitted of Centre for Environmental Planning and Techology,Ahmedabad,India.

Maharjan, S. (2016). Earthquake emergency preparedness and response: A case study of Thecho VDC. Master's thesis, Central Department of Geography, TU, Kathmandu, Nepal.

NRCS (2015). Disaster Risk Management Plan of Thecho VDC. Kathmandu: Nepal Red Cross Society (NRCS).

NSET (2004). Disaster inventory /Information Management System in Nepal. Kathmandu: NSET.

NSET-Nepal. (2012). Disaster Preparedness and Response Plan Framework For Safe Dringking Water in Lalitpur Sub-Metropolitan City, Nepal.kathmandu:NSETNepal.

Shah, R. K. (2003). Seismic Capacity Evaluation of Masonary School Building. Unpublished M.Sc. Thesis Submitted to Department of Civil Engineering, Pulchowk.

Spence, W., William, S. A., \& Choy, G. L. (1989). Measuring the size of an earthquake. Earthquakes and Volcanoes, 21:1. 54:63.

Thode, H. J. (2002). Testing for normality. New York: Marcel Dekker.

VDC office Thecho. (2008). Village Development Committee Profile. Thecho, Lalitpur: VDC.

UNDP. (2013). Livelihoods \& Economic Recovery in Crisis Situations.New York: UNDP, Bureau for Crisis Prevention and Recovery Livelihoods and Economic Recovery Group.

UNDP/ERRRP. (2009). Earthquake Vulnerability Profile and Preparedness Plan of Pokhara by Metropolitan. Kathmandu: Unite National Development Programm/ Earhtquake Risk Reduction and Recovery Preparedness programme.

USGS. (2015).The M7.8 Nepal Earthquake, 2015 - A Small Push to Mt. Everest. . Retrieved from https://earthquake.usgs.gov/research/everyone/nepal2015/

Villacis, C., Cardona C. N., \& Tucker, B. (2000). Implementation of fast earthquake scenarios for risk management in developing countries A Conference paper presented at 12th World Conference on Earthquake Engineering, Auckland, New Zealand.(12WCEE2000).

Walton, N. (2014). Assessing Seismic Risk Reduction in the Kathmandu Valley using Cost-Benefit Analysis to Evaluate Loss Prevention in Schools. Unpublished MSc Dissertation,Adam Smith Business School, University of Glasgow,Scotland.

White, G. F. (1945). Human Adjustment to Floods. Department of Geography Research Paper. Chicago: The University of Chicago.

World Bank. (2008). World Bank Good Practice Notes: Disaster Risk Reduction. New York:World Bank. 